\title{
VIAJES DE ESPAÑOLES POR LA ESPAÑA DEL SIGLO XVIII
}

Si el lema de Montaigne era: Que sais-je?, el del hombre del siglo xviII era, según declaraba Voltaire: Que ne sais-je pas? Poco era lo que creía ignorar, en comparación con otras épocas menos ilustradas, y ese poco podría llegar a saberlo mediante la observación, el estudio, los viajes. Mientras Montaigne estudiaba para conocerse, escarbando en su propia conciencia, y apuntaba sus monólogos consigo mismo en forma de Ensayos, el hombre del siglo xvin se explayaba por todo el mundo para dar a conocer lo que observaba, y discurría en forma de Ciartas. Y al viajero del siglo xvir no le importaba tanto subrayar lo esencialmente humano, lo que todos los hombres tenían en común, como señalar y explicar lo que les distinguía, lo que diferenciaba a un pueblo de otro, a una cultura de otra. Aunque hablaba mucho del género humano y de la humanidad y daba por supuesto que todos los hombres eran iguales -o lo habian sido-, le gustaba observar al hombre concreto en lo que tenía de más particular, y a los pueblos en sus costumbres más propias y "pintorescas", para luego comunicar sus observaciones en Viajes, escritos muchas veces en forma de cartas. Y estos incontables Viajes los leía un público cada vez mayor. Jovellanos apuntaba en su Diario los Viajes que leía: los de Cook, de Carteret, del Comodoro Byron, de Wallis, además de los que escribían los extranjeros que habían viajado por España: Clarke, Townsend, Jardine, Peyron. También en España cundía la fiebre de los viajes, y viajaban españoles por Italia - Luzán, Ponz, Goya-, y por Francia e Inglaterra muchos más, y difundían sus observaciones en cartas dirigidas a sus amigos y en Viajes escritos para todo el público culto.

Más notable aún es el hecho de que los españoles empezaron a viajar por España. Ya había declarado Quevedo en su España defendida, en 1609: “... es razón que despertemos y logremos parte del ocio que alcanzamos en mostrar lo que es España y lo que ha sido siempre". Mostrar lo que había sido y lo que era España, tal fué el propósito de los esforzados eruditos y fervorosos peregrinos que recorrían toda España, explorando archivos, reuniendo documentos, medallas, inscripciones, midiendo monumentos, caminos y puentes, observando el campo y sus plantíos, los pueblos y sus habi- 
tantes, apuntando todo lo que veían para luego darlo a conocer. Pero si nos admiran el celo y la constancia con que estos viajeros se afanaban por conocer toda la realidad española, nos asombra también la actualidad de las observaciones y reflexiones que hacían acerca de esta realidad: muchas veces son idénticas a las que harían los escritores de la generación del 98 . No es de extrañar que sea así, puesto que les anima a unos y.otros el mismo espíritu crítico, la misma conciencia y preocupación de España, el mismo esfuerzo de sobreponerse a un estado de postración general en un momento de crisis - la guerra desoladora sobre la sucesión de la Corona española a principios del siglo xvin, y el desastre del 98 . Pero es mucho también lo que les distingue: los del 98 no tenían ya las grandes ilusiones de los ilustrados, la ilusión de la Razón, de la Verdad, de la Historia. Si éstos creían encontrar soluciones a los problemas nacionales acopiando datos y documentos, aquéllos, aleccionados por dos siglos de experiencia que habían minado los cimientos del racionalismo optimista y del positivismo científico, sabían que habría que cavar mucho más hondo, ya no en archivos, sino en la conciencia misma de cada español. Así es que, mientras los infatigables eruditos del siglo xvin pretendían únicamente reunir hechos exactos con los cuales se pudiera reconstruir la historia de España, los escritores del $9^{8}$ crean obras artísticas, en las cuales procuran expresar el sentido íntimo de esa misma historia.

Azorín, el autor contemporáneo que con más simpatía y comprensión ha estudiado el siglo XVIII, comenta en uno de sus libros el estado de ánimo español a fines del siglo xvil y principios del siguiente, y escribe que, acabada la era de las aventuras, "la energía de hazañas y fechorías, heroicidades y apreturas - propio pasto de novelas y comedias - se transforma en investigación laboriosa en archivos y bibliotecas ... Al poeta y al aventurero reemplaza el erudito; se trata sencillamente de una transformación de fuerzas, motivada por las nuevas condiciones sociales en que se vive" ${ }^{1}$. En efecto, los literatos que nacieron a fines del siglo XVII y a principios del xviII se dedicaron a investigaciones para deshacer errores y para aumentar el caudal de verdades; Feijóo nació en 1676, adelantándose a los demás; Torres Villarroel en 1693, Montiano en 1697, Mayáns en 1699; en el año de 1702, fray Martín Sarmiento, fray Fnrique Flórez, don Juan de Iriarte, Luzán, y en 1703 el P. Isla. Otro grupo de eruditos nació por la tercera década: el P. Burriel en 1719, Velázquez en 1722, Campomanes en 1723, Ponz y Sánchez en 1725 .

Confesaba el célebre y doctísimo Sarmiento: "Cada día salgo de algún error, y mudo de dictamen, y en virtud de las nuevas

1 El alma castellana, Madrid, 1919, pág. 155. 
luces que hallo en mis libros. Y tan lejos de hallar repugnancia en esto, me complazco en mudar de dictamen, y en tocar mís de cerca con el dedo la verdad que tanto deleita"'. Estudiaba en la calma de su celda, entre sus miles de libros, recogiendo "apuntamientos" -sobre antigüedades y etimologías, sobre historia, geografía y poesía- que luego suministraba con extraordinaria generosidad a sus • amigos, el P. Feijóo y otros muchos, para quienes era un "mar de erudición". No le importaba a Sarmiento "dar a luz sus obras ni ganar fama de literato, pero los más de los eruditos sí querían ganar fama de tales y dar a conocer, no sólo a sus compatriotas, sino a todas las naciones cultas, los tesoros que descubrían. De éstos era Mayáns, bibliotecario regio e insigne investigador, que no dejaba de anunciar sus trabajos en las infinitas cartas que mandaba al extranjero, como en esta que dirigió al señor Ewaldo de Klopman, caballero de Curlandia, en la cual decía:

Mi regocijo el que me causa su afición a cultivar la lengua Española, que yo tanto amo, a tiempo que en otros muchos, o la corrompen, o se descuidan de conservar sus más preciosas memorias. Y me duele tanto, que uno de los principales fines que he tenido para escribir una Rhetórica española, ha sido manifestar los thesoros de la Lengua Castellana, haciendo ver i admirar su abundancia, propiedad, magnificencia, elegancia, i todas las demás bondades del Estilo perfecto, prácticamente egecutadas en los escritos de muchísimos Españoles, cuyas obras son mui raras i mui poco leídas?.

La misma afición a estudiar los monumentos de la primitiva literatura y a buscar sus orígenes motiva cuatro investigaciones independientes de los orígenes de la poesía española - las de Velázquez, Sarmiento, Floranes y Sánchez-, y lleva a Sánchez al descubrimiento del Poema del Cid, mucho antes de que se descubriera un poema épico en Francia 4 .

Así, pues, el afán de estos investigadores fué ver y hacer ver todo lo que se ignoraba o se conocía mal, fueran tesoros artísticos, documentos históricos o hechos científicos. Los nuevos conocimientos,

2 "El por qué sí y el por qué no", en Diario de los Eruditos, VIII, págs. 111-112.

${ }^{3}$ Cartas morales, militares, civiles $i$ literarias de varios autores españoles, recogidas y publicadas por D. Gregorio Mayáns, Valencia, 1773, vol. IV, pág. 53 .

${ }^{4}$ Luis Joseph Velázquez, Origenes de la poesia castellana, Málaga, 1754; fray Martín SARmiento, Memorias para la historia de la poesia y poetas españoles, obra póstuma, Madrid, 1775; Thomás Antonio Sánchez, Colección de poesias castellanas anteriores al siglo xy, Madrid, 1779-1790, 4 vols.; RAFAfL Floranes, Sobre los origenes de la poesia castellana, opúsculo inédito publicado por Menéndez Pelayo en RHi, XVIII, 1908, págs. 295-431. 
además de exactos, habían de ser útiles; según el criterio de la época, los estudios que no producían utilidad eran frívolos, si no perjudi-

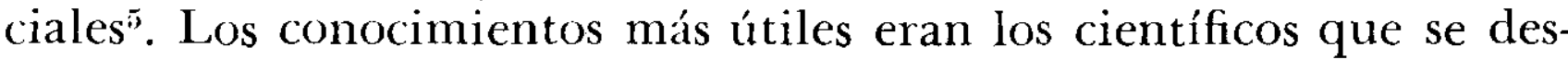
cubrían por medio de viajes de investigación científica, como el famoso viaje de Jorge Juan y de Antonio de Ulloa, que había encargado el gobierno y que hizo publicar a sus expensas Fernando VI (Relación del Viage á la América meridional hecho de orden de S. Mag. para medir algunos grados de meridiano terrestre, y venir por ellos en conocimiento de la verdadera figura y magnitud de la Tie. rra..., Madrid, 1748, 5 vols.), o los interesantísimos viajes que hizo por la América meridional el marino Félix de Azara, levantando cartas exactas y estudiando la historia natural del Paraguay y del Río de la Plata, o el viaje notabilísimo de Antonio Josef Cavanilles, Observaciones sobre la historia natural, geografia, agricultura, población y frutos del Reyno de Valencia (Madrid, 1795-1797, 2 vols.).

Entre las vastas empresas oficiales, estaban los llamados "Viajes literarios", expediciones de investigación arqueológica e histórica, como las que emprendieron el P. Burriel, Pérez Bayer, Velázquez, el Conde de Lumiares, Ortiz, Cornide, Villanueva y otros. Nos proponemos aquí comentar una de estas expediciones literarias oficiales, la de Velázquez, y examinar luego unos cuantos de los Viajes particulares, los de Ponz, de Jovellanos, de Zamora y de Viera y Clavijo.

Don Luis Josef Velázque», Marqués de Valdeflores, era regidor perpetuo de Málaga, caballero de la Orden de Santiago, individuo de las Academias españolas y de la de Inscripciones y Bellas Artes de París. Adicto a la escuela neoclásica francesa, formaba parte, con Luzán, con Porcel y con Montiano, de la Academia de Buen Gusto que se reunía en casa de la Condesa de Lemus por los años de 1749 a 1751. En su Noticia del viage de España (Madrid, 1765), como en otras obras ${ }^{6}$, se muestra un historiógrafo laborioso, de más asiduidad que criterio. Explicaba en la Noticia que se había emprendido esta expedición literaria, de orden del Rey, porque se proyectaba una nueva historia general de España desde los tiempos más remotos hasta el año de $15^{16}$, la cual se sacaría únicamente de los escritores y monumentos originales y contemporáneos. Al P. Burriel y a Pérez Bayer se les había encargado revisar los documentos de historia eclesiástica, y a Velázquez reunir los de historia civil. Con este fin viajó por las dos Castillas, por Extremadura y por toda

"Véase J. Scrrain, "La notion de l'utile dans la culture espagnole à la fin

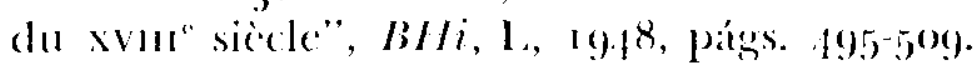

"Además de sus Origenes, las Conjeluras sobre las medallas de los reyes godos... y los Anales de la nación española desde el tiempo más remoto... (Málaga, 1759); en la B. N. M. (ms. 17546) se conservan sus Cartas inćditas a Montiano. 
Andalucía reconociendo documentos, mientras un diseñador que llevaba consigo sacaba apuntes de los monumentos examinados. Se trataba de escudriñar todos los monumentos que pudieran ser de alguna utilidad para la historia general de la nación, a saber: diplomas; medallas e inscripciones, monumentos de pintura, escultura y arquitectura, muebles y demás utensilios de la vida civil, y los antiguos escritos sobre los diferentes ramos de los conocimientos humanos. Por si esto no bastara, había de indagar los nombres de los antiguos pueblos y recoger materiales de geografía para mapas exactos. Y concluídas estas investigaciones, había que formar una relación completa de sus viajes, que es lo que hace en su Noticia. En los dieciocho años que consagró Velázquez a estos viajes "literarios", recogió más de sesenta volúmenes de documentos antiguos. Al recorrer pueblos y archivos, apuntaba en cartas a su amigo Montiano sus impresiones de viaje, como éstas de Extremadura, tan semejantes a las que la misma provincia dejaría veinte años después en el capitán Cadalso:

Amigo, téngame V. lástima, q. lo q. viajo es la Groenlandia de España. No he visto gentes más brutas, más salvages... ¡Lo q. yo me lisongeaba en Madrid de averiguar las cosas a fondo en este viage! ¿Creerá $V$. que ha havido lugar en q. no he podido averiguar su verdadero nombre, examinando a los mismos vecinos q. lo habitan? Xaraicefo, Zaraicefo, Zerecefo, estos $\mathrm{i}$ otros nombres tiene uno por donde pasé, y todavía ignoro cómo lo he de poner en el Mapa... (Mérida y Abril 26 de 1753).

A poco de entregar la Noticia del viage de España, sufrió Velázquez una injusta persecución, víctima del ruidoso motín de Esquilache; fué preso de orden del Rey y pasó los últimos años de su vida en los castillos de Alicante y de Alhucema. Estando en el de Alicante conoció al joven Conde de Lumiares, a quien sus padres habían hecho encerrar por ciertas travesuras; procuró Velárquez estimularle a la lectura de los buenos autores, y fué tal la afición que adquirió el Conde al estudio de las antigüedades y a la numismática, que dedicó el resto de su vida a formar museos y gabinetes, haciendo varios viajes por España para estudiar y coleccionar medallas, estampas y otros documentos antiguos.

A veces, se emprendían viajes oficiales de investigación para corregir errores que habian difundido viajeros extranjeros; con este motivo se encargó a Joseph Francisco Ortiz - traductor de Vitruvio y de Adam Smith - que hiciera un viaje arquitectónico-anticuario por las provincias de España para reconocer y dibujar las antigüedades romanas que existían en ellas. Han dejado todos estos viajeros 
eruditos, comisionados por el despotismo ilustrado, un acervo inagotable de datos que los historiadores del siglo $\mathrm{xIx}$ y del $\mathrm{xx}$ han podido y sabido aprovechar.

Pero muchos eruditos viajaban por su cuenta, y no se dedicaban exclusivamente a amontonar documentos. De éstos era Ponz, que se propuso, en los dieciocho tomos de su Viaje de España (Madrid, 1772-1794), dar a conocer al lector medio de España y de todos los países cultos "los edificios y obras públicas que existen en España, manifestando el artificio y excelencia de algunos, así como la falta de inteligencia de otras" ${ }^{\prime}$. Había dedicado Ponz muchos años al estudio y a la práctica de las nobles artes, en Madrid y en Roma. A su vuelta de Italia, se le había encargado hacer retratos de sabios españoles para la Biblioteca del Escorial. Y al cumplirse en 1767 la orden de expulsión de los jesuítas, le había comisionado Campomanes para escoger, en las casas y en los colegios de la Compañía, los mejores cuadros de pintores nacionales y extranjeros para la Academia de San Fernando. Al recorrer las provincias de Andalucía en cumplimiento de esta comisión, se le había ocurrido la idea de su Viaje. En la Advertencia que puso a la tercera edición del tomo primero, en 1787 , declara no haberlo emprendido por orden oficial, sino "espontáneamente, aunque después quiso Su Majestad honrarle por este trabajo, y contribuir generosamente a que lo terminase"; tampoco era su propósito, como se decía, refutar al P. Norberto Caimo, a quien atribuía la obra intitulada Lettere d'un vago italiano ad un suo amico (Lucca, 1766; trad. al francés en L'Année Littéraire, 1772). Sólo quería servir al bien público y al adelanto de las bellas artes, dando a conocer los monumentos desconocidos $\mathrm{u}$ olvidados, "celosísimo de que se conozca lo malo y se abrace lo bueno". Es admirable su amplitud de criterio, pues sabe estimar las obras de todas las épocas menos la inmediatamente anterior a la suya. Juzga al siglo xvi como la mejor época del arte. No obstante, encuentra mucho digno de elogio en las grandes catedrales de la Edad Media; la de León, por ejemplo, "es una de las más gentiles y magníficas catedrales que en el estilo gótico pueden verse ...", y la palabra gótico no tenía para él el sentido denigrante que en la misma época tenía en inglés: en esta lengua equivalía a 'bárbaro', y se empleaba para desprestigiar el arte y la filosofía de la Edad Media. Jovellanos expresaba la misma admiración que Ponz por los templos góticos, elogiándolos "por su inmensa grandeza, por el lujo de sus adornos y por la delicadeza de su trabajo" 8 . No es que sintiera especial predilección por el arte de la Fdad Media; lo estimaba por antiguo y por nacional. De igual modo apreciabạ los antiguos monumentos de la lengua caste-

' Ed. de Madrid, 1947, págs. 2 1-22.

"Elogio de las bellas artes, en BAAEE, vol. XLVI, pág. $35^{1 .}$ 
llana, que le parecía, desde el siglo xıII, "despojada de su antigua rudeza, y cubierta ya de esplendor y majestad". Lo que sí censuraban Ponz y Jovellanos en algunos monumentos medievales era lo que les parecía falta de proporción o armonía, y que resultaba de las "tristes añadiduras" que se habian hecho en los espléndidos edificios antiguos, sobre todo los retablos modernos, "de una ridícula y extravagante fealdad". Se ensañaba Ponz, por todo el Viaje, contra los monstruosos y bárbaros retablos y fachadas de Churriguera o de los de su escuela, pareciéndole una calamidad universal el depravado gusto de sustituir los bellos y sencillos tabernáculos antiguos por los disparates y abortos modernos. Fuera de los ornatos extravagantes y los enormes desaciertos de la talla moderna, casi todo lo juzgaba admirable. En la crítica de pintura mostraba criterio aún más amplio; de los cuadros del Greco, por ejemplo, decía que, a pesar de sus extravagancias, manifestaban "mucho espíritu, manejo de colores, inteligencia de luces, y otras cosas que con razón atraen la curiosidad".

No se limitaba Ponz a las observaciones artísticas. Además de medir y describir minuciosamente todos los monumentos, explicaba la historia de los edificios y la vida de los artistas que habían trabajado en ellos, así como el origen y la historia de las ciudades y sus fundadores. No era ajeno a la pasión anticuaria de la época, pero siempre la dominaba, como cuando al estudiar las antigüedades romanas de Mérida, declaraba: "Conviene saber lo que fué, pero más del caso juzgo entender lo que es al presente, y mejorarla". Siempre juzga de acuerdo con la norma práctica y progresista vigente, en sus numerosas observaciones sobre la vinculación de las tierras, la falta de cultivos, la despoblación, la necesidad de caminos y puentes y árboles. (Es una obsesión suya la hostilidad de los españoles para con los árboles). Comenta los temas ineludibles de todos los viajeros, a saber, los caminos ásperos y las posadas inhospitalarias, e indaga causas y propone remedios. Todo se podía remediar, con el estudio, con las luces y con el esfuerzo. Cuando observa el campo, no es como artista, sino como economista, lleno de nostalgia por los frutos y granos, pastos y arboledas de antaño, y siempre soñando con proyectos para restaurar la antigua prosperidad.

Con razón dijo Menéndez Pelayo que "el Viaje de Ponz es más que un libro: es una fecha en la historia de nuestra cultura"' tradujeron varios tomos al francés, al italiano, al alemán, y hasta hoy el Viaje de España sirve de guía a todos los viajeros o lectores que quieran conocer los tesoros artísticos que encierran las distintas regiones de Fspaña. Parece inverosímil que haya recorrido tantas tierras, estudiado tantos monumentos, apuntado tantas y tan exactas noticias. Sabemos que contaba con la colaboración de muchos eruditos y

" Historia de las ideas estéticas en España, Madrid, 1947, vol. III, pág. $5^{6 .}$ 
literatos contemporáneos que le proporcionaban noticias, de Jovellanos sobre Asturias, de Rodríguez Lazo sobre Barcelona, del P. Sarmiento sobre muchos asuntos. No obstante esta ayuda, nos parece prodigioso el esfuerzo sostenido por tantos años, el amor patrio con que daba a conocer lo que descubría, y no menos prodigioso el poder de recrear la historia de España a través de sus monumentos artísticos de todas las épocas. Por otra parte, no hay obra que nos revele mejor que el Viaje de España de Ponz el modo de pensar y de sentir del español del siglo xviII.

Jovellanos ya no era hombre exclusivamente del siglo xvin, por lo menos en su manera de sentir. Pero era muy del siglo xviII en su apetito desaforado de saber para instruir y en su fe en el progreso. No le bastaba describir lo que eran Castilla y León en sus días y lo que habían sido en el pasado; procuraba mostrar lo que serían con el tiempo, cuando se hubieran llevado a cabo los grandes proyectos de canales y de irrigación:

Figúrese usted concluídos los canales de Castilla y Campos...., figúrese que las aguas del Eresma, del Pisuerga, el Carrión, el Duero, el Voltoya y el Ezla extienden el riego y la navegación ... ; que en consecuencia se dividen sus fértiles territorios en suertes pequeñas ...; que crecen con el producto las subsistencias, con las subsistencias los hombres, y con los hombres el trabajo, la abundancia, la alegría y la felicidad ... ${ }^{10}$

Muchos años después, Moratín le escribiría desde Aviñón que, pasando por el canal de Lenguadoc, sentía envidia al recordar que el canal de Campos se había empezado, "como se empieza todo lo bueno de España", para no concluirse jamás, y profería esta amarga reflexión: “ ¿No es desgracia nuestra que cuanto se hace, dirigido a la utilidad pública, viene otro al instante que lo abandona o lo destruye? ${ }^{11}$ Ya se enteraría Jovellanos por su propia experiencia, pero al escribir las Cartas a Ponz todavía le quedaba la ilusión de que, haciendo la guerra a la ignorancia y al error, sería posible remediarlo y mejorarlo todo. Aunque realizaba los más de sus viajes para cumplir encargos del Rey - examinar minas de carbón de piedra, medir caminos, visitar el canal de Campos o el colegio de Calatrava-, no dejaba de apuntar todo lo que observaba: tierras sin cultivar, pueblos o castillos que se desmoronaban, conventos y fábricas, arboledas y minerales, usos y costumbres, antiguos monumentos, cuyos archivos reconocía, copiando datos para sus propios archivos y para su joven amigo y

${ }^{10}$ Cartas a Ponz, en $B A A E E$, vol. I, pág. $276 a$.

11 Leandro Frenníndez de Moratín, Obras póstumas, Madrid, 1867 , vol. III, pág. 110 (carta de 28 de agosto de 1787 ). 
discípulo, Ceán Bermúdez. Son estas observaciones más personales, menos objetivas que las de Ponz; revelan más sensibilidad tanto para la naturaleza como para el arte, y más sentimiento humano. Le dolía a Jovellanos la pobreza que veía en los lugares despoblados, por ejemplo en Mansilla de las Mulas, pueblo murado, que antes había tenido siete mil vecinos, y que ahora estaba reducido a unos ciento veinte: “CCómo, pues, tanta pobreza? Porque hay valdíos; porque las tierras están abiertas; porque el lugar es de la señoría del Duque de Alba; porque hay mayorazgos, vinculaciones, capellanías ... iOh suspirada ley agraria !", apunta en su Diario, refiriéndose a su Informe de ley agraria, que preparó para la Sociedad Económica de Madrid $^{12}$. Creía que por medio de buenas leyes todo se podría reformar, y que estas leyes serían "un efecto infalible de la propagación de las luces: quando la opinión las dicte, la autoridad tendrá que establecerlas, quiera que no".

Las páginas de sus cartas y del Diario están sembradas de meditaciones sobre el arte y sobre la naturaleza, como en este apunte sobre San Andrés de Trubia: "Es sitio delicioso a la margen de las sonoras aguas y a la sombra de un hermoso avellano. Todo es poético ... iOh Naturaleza! ¿Qué desdichados son los que no pueden disfrutarte en estas augustísimas escenas, donde despliegas tan magníficamente tus bellezas y ostentas tu majestad!"13 Cuando, más tarde, se convierte la ilusión en amargura y en desesperación el optimismo, quedan incólumes su pasión por la patria -grande y chica- y el amor al estudio y al arte. Estando confinado en el castillo de Bellver en Mallorca, entre 1801 y 1808 , escribiría para su amigo Ceán la Carta-memoria sobre el castillo de Bellver, que es otra relación de viaje, un viaje hecho a través de la historia de Mallorca, y revelaría todas sus bellezas artísticas, que tan hondamente sentía.

A todos los viajeros que recorrieron la España del siglo xvıI les aguijoneaba el anhelo de conocer y de dar a conocer, a Campomanes, en su Viaje a Extremadura ${ }^{14}$, como al P. Flóre, insigne autor de la España sagrada, cuyos viajes se cuentan detalladamente en las Noticias de la vida y escritos del Padre ... Flórez que dió a luz el agustino fray Francisco Méndez (Madrid, 1780). También excitaba a los espíritus más modestos el anhelo de saber, la avidez de observar. Cavanilles contaba que había conocido en el pueblo de Castelló a un

12 Véase Edith F. Helman, "Some consequences of the publication of the Informe de ley agraria by Jovellanos", en Estudios hispánicos: Homenaje a Archer M. Huntington, Wellesley, Mass., 1952, págs. $253^{-273 .}$

${ }^{13}$ Diarios, ed. de Madrid, 1915, pág. 79. [Sobre cl sentimiento de la naturaleza en los Diarios de Jovellanos véase el artículo de ÁNGel deL Río en este mismo volumen de la $N R F H$, págs. 630-637].

${ }^{14}$ B. N. M., ms. K. 7728. 
boticario que empleó dieciséis años en recorrer la costa, los montes, campos y barrancos para formar su flora, y que había conseguido dibujar y animar con colores naturales como setecientas plantas, y eso sin libros, sin haber visto jardines ni gabinetes de historia natural. Y hemos visto un Diario inédito de los siete viajes que hizo por Cataluña, entre 1785 y 1790 , don Francisco de Zamora, que, al ser nombrado por el Rey a la plaza de alcalde del crimen, formó la idea de ver la provincia, para poder desempeñar mejor las obligaciones de su empleo. Caminaba a caballo o a pie, acompañado de un criado, y visitaba hospitales, monasterios, archivos y bibliotecas, escuelas y fábricas, apuntando todo lo que observaba y todo lo que padecía, pues no era nada fácil "andar por montes y valles, de pueblo en pueblo, preguntando a quien teme responder, observando para que no le engañen con las respuestas, apuntando de día para formar el Diario la noche, dormir poco, comer mal y gastar mucho, sin ningún auxilio del Rey ni del público..."15

Pero la relación de viajes más amena y entretenida, y la de más valor literario, es la del Viage a la Mancha en el año I774, escrita por el abate don José Viera y Clavijo, ilustre historiador de Canarias, uno de los mejores prosistas del siglo Xviri ${ }^{16}$. Aunque este Viaje quedó inédito hasta que Morel-Fatio lo encontró entre los manuscritos de la Biblioteca Nacional de París en 1890 , es posible que el autor hubiera pensado mandarlo a un periódico, puesto que ponía este subtítulo: "Adición a la historia general de los Viages que sale en el Diario de Madrid". Es que en el siglo de las luces se leían los Viajes en la prensa periódica con la misma voracidad que los folletines en el siguiente.

Era Viera ayo del Marqués del Viso, hijo primogénito del Marqués de Santa Cruz. En este Viaje, que se verificó entre el 9 de septiembre y el 9 de octubre de 1774 , en dos coches de colleras, acompañaba el autor a sus señores, que iban a sus tierras en Valdepeñas, en Santa Cruz de Mudela y en el Viso. Cuenta con mucho gracejo todo lo que veían en el camino y en todos los lugares donde paraban. De camino se leía "el manual que precisamente deben llevar los peregrinos que van en romería a aquellos santos lugares, las Aventuras del famoso caballero andante don Quixote". Visitan la venta de Quesada, "tan digna de eterna memoria por el manteamiento de Sancho Panza, sin embargo de que la actual ventera ni siquiera había oído nombrar a $\mathrm{D}^{\mathrm{n}}$ Quixote, con ser así que es quinta o sexta nieta de MariTorne\%, o mienten las fisonomías. Ya dixo un hermano suyo que ese tal $\mathrm{D}^{\mathrm{n}}$ Quixote, a lo que él creía, había sido cierto guapo de la Man-

15 B. N. M., ms. $184 \% 9$.

"15 Véase A. Moret-Fatio, Études sur l'Espagne, Paris, 1890, Apéndice VI, págs. 389-116; y José Viera y Cilavijo, Noticias de la historia general de las islas de Canaria, Madrid, $1772-1789,4$ vols. 
cha que vivió ahora mil y ducientos años. Nos admiró la exactitud de chronología"17.

Por fin llegaron a "aquellas primeras viñas y olivares que recrean con su verdor los ojos del caminante, cansado de tantas leguas de tierra seca y rastrojos". A dos leguas de Valdepeñas, llegan a su encuentro la solemne diputación del Ayuntamiento de Valdepeñas, otra diputación del convento de los padres trinitarios descalzos, partidas de muchachos y mujeres y, a poco trecho, berlinas con los vecinos principales. La entrada de los ilustres viajeros en Valdepeñas se hace en este orden: primero va el aposentador, Antonio Caminero, que "iba de batidor en un cavallo de cuello aguileño, con montera atrabesada, colodrillo reverendo, casaquilla hueca, etc."; luego los dos insignes tontos, Francisco de Santa Cruz y Casimiro del Viso, "capitaneando una innumerable multitud de muchachos"; seguían el coche en que iba el joven Marqués, el coche de cámara con la familia, la calesa del dibujante Carnicero y las berlinas de las diputaciones y de los caballeros hidalgos. Iba la comitiva acompañada de patrullas de hombres y mujeres, hasta que llegaron todos a la parroquia, donde entraron los señores, con "órgano, hisopo, vivas y repiques". En Valdepeñas pararon ocho días, y vieron las nuevas fábricas, de jabón y de paños, establecidas por orden del Marqués de Santa Cruz en utilidad de sus vasallos, donde trabajaban hombres, mujeres, chicos y hasta estropeados. Examinaron la nueva posada que se hacía, visitaron las escuelas de niñas y de muchachos, observando cómo éstos leían y escribían y cómo se ejercitaban sobre el catecismo de Fleury. Al pasar por la cárcel, se mandó soltar a uno de los dos presos. Y por fin, vieron un lugar muy venerado en Valdepeñas, la bodega, que se componía de largos lagares y otras galerías, "cuyas inmensas tinajas... están bien empotradas en número de 180 y forman un intrincado laberinto, o, por mejor decir, una real biblioteca de tomos y atlas de más de a folio. En esta biblioteca hay también sala separada para los libros prohibidos, quiero decir para las tinajas del aguardiente ..."18 Por la noche, "ópera manchega", esto es, una hora de seguidillas y "orquesta de un violín, dos guitarras y un tiple".

En Santa Cruz y en la villa del Viso se repiten los mismos recibimientos, visitas y diversiones. Hace revivir el autor las costumbres señoriales, así como los usos y costumbres populares, tan sanos y sencillos, y a los cuales se ajustan perfectamente los señores. Éstos son recibidos con cariño y con regocijo por los campesinos, gente muy trabajadora y apegada a sus tradiciones. Es natural que el abate Viera nos dé una impresión muy favorable de los Marqueses. Pero también es cierto que era el de Santa Cruz uno de los nobles españoles que

17 Viage a la Mancha, en Morel-Fatro, op. cit., págs. 393-394.

1s Ibid., pág. $39^{8}$. 
mejor cumplían sus deberes heredados; visitaba a menudo sus tierras, las hacía cultivar, y velaba por sus vasallos, fundando escuelas y estableciendo fábricas. Era un hombre de su siglo; viajó por toda Europa, y en París concurrió, con su hijo y con Viera, a la Escuela de la Física Experimental de M. Sigaud de la Fond; de vuelta en Madrid, hizo instalar en su palacio máquinas e instrumentos para demostraciones físicas, y desde el jardín de su palacio hizo volar uno de los primeros globos aerostáticos que se vieron en Madrid. Huelga afirmar que este entusiasmo por las nuevas ciencias no influía en lo más mínimo en su antiguas y arraigadas creencias. No se trataba nunca de importar, con los conocimientos científicos, costumbres nuevas y extrañas. Lo antiguo se conservaba por ser antiguo y por ser propio.

Sin preocupaciones económicas y sin el propósito de reformar o mejorar lo que existía, describía Viera con espíritu festivo lo que veía, sin más ni más. Le interesaban sobremanera las costumbres populares, y observaba hasta cómo hablaban los aldeanos, cómo decían belrina por berlina, y cómo usaban antiguos términos como ogaño, decillo, hacello, etc. En el Viage a la Mancha, como en muchos escritos de Jovellanos, tenemos ya esbozados los cuadros de costumbres que escribirían los "costumbristas" de la primera mitad del siglo XIX.

Los literatos y eruditos del siglo xvin que tanto se esforzaban por descubrir y dar a conocer a España, así como todas las manifestaciones del espíritu español a través de su historia, no eran, por lo común, de Castilla, sino de las provincias periféricas: Viera de Canarias, Jovellanos de Asturias, Ponz, Mayáns, Pérez Bayer y Cavanilles de Valencia, Velázquez de Málaga, Cadalso de Cádiz, y así muchos más. Hemos visto con qué fervor recorrían y estudiaban la patria chica y la grande, y con qué celo apuntaban sus indagaciones y observaciones en sus Viajes. Si las luces venían de fuera, la realidad que iluminaban era la propia, actual e histórica. Además, las famosas luces se refractaban al pasar por la densa opacidad de la larga y gloriosa historia de España y por el carácter tan especial de los españoles. Así es que, muy lejos de ser el siglo xviII puro remedo de lo extranjero, es el período en que se reconoce, se aquilata, se reconstruye lo nacional.

Edith F. Helman 